\title{
Quality Enhancement of Intermediaries: A Study of Good Practice in Education Administration
}

\author{
Rucha Gujar \\ YCM Open University, Nashik, Maharashtra, India
}

\begin{abstract}
Highly populated countries have to cater the education to masses and hence have requirement of different education set ups. Due to economy constraints, the universities in such countries cannot own campuses of all requirements on their own; hence the programmes are run through the study centres. The study centres are already developed with required infrastructures and human resources. Maintaining quality in such situation is the big challenge. Hence universities have to develop some parameters for the measurement of quality of study centres. The parameters are based on the smooth working, delivery of the educational programmes, activities of individuals making up the institutions, motivation to counsellors, coordinators and institution owners, to improve their performance and infrastructures. The present research paper is based on investigation of documental proofs of infrastructures, human resource availability, authenticity and accountability regarding documents of the institution, previous enrolment and examination records of the study centres of the School of Continuing Education of Yashwantrao Chavhan Maharashtra (YCM) Open University, Maharashtra India. Documents and records of 67 study centres are investigated based on 15 indicators. The data collected through the documents, interviews and cross examinations is analysed. On the basis of data, the number of efficient, poor performing study centres is segregated. The problems inherent in the system are identified and suggestions proposed for the improvement in the system. This exercise proved to be beneficial for the enhancement in the services from university to the study centres and from study centres to the students, by reducing the burden of excess work for providing services to nonfunctioning study centres.
\end{abstract}

\section{Introduction}

The Yashwantrao Chavan Maharashtra Open University (YCMOU) was established in July 1989 by Act XX- (1989) of the Maharashtra State Legislature, India. It is a member of various prestigious associations and bodies like the Association of Indian Universities (AIU), Association of Commonwealth Universities (ACU), Asian Association of Open Universities (AAOU), Commonwealth of Learning (COL), Canada to name a few. The main aim of the YCMOU is to become a Mass Varsity and to make available the education to the common man, educational programmes that are of practical use in his day-to-day life and those that provide better prospects for the future. The YCMOU has its headquarters at Nashik Maharashtra India and provides support to its learners through study centres, which are spread all over the State of Maharashtra.

Mission of YCMOU, Maharashtra, India: Through technical, vocational, professional and liberal education programmes, application of modern communication technologies and adoption of the distance education methodology, YCM Open University strive towards developing an Innovative, Flexible and Open system of education.

Special features of Education provided by YCMOU, Maharashtra, India

- Emphasis on imparting vocational and technical skills.

- Use of Latest Information and Communication Technologies.

- Relaxed entry rules, flexibility in course combinations and credit transfer facilities.

- Extensive network of study centres.

- Scientific system of student evaluation.

- Special attention to Quality.

- Thrust on empirical Research.

- Recognition of our degrees and diplomas by other universities and professional bodies.

Based on the features mentioned above, YCM Open University, India operates the education system through the extensive network of the study centres 
spread all over the Maharashtra in India. The study centresare located in various cities and villages of Maharashtra. They operate as mediators and deliver the educational programmes of YCM Open University to the students, as per the guidelines of the YCM Open University. The study centres are not the own campuses of the University but are recognised campuses for the delivery of YCMOU programmes. By the turn of the millennium almost every economically developed country understood the importance of measuring the performance of mass education with comparable indicators. These indicators have to be linked to the activities of individuals making up the institutions and used to develop motivation to counsellors, coordinators and institution owners, to improve their performance and infrastructures. The efficient operation of mass education institutions is contingent on having access to appropriate performance indicators and on linking this body of information to a well-functioning evaluation.

\section{Methodology}

The research paper is based on investigation of infrastructures, human resource availability, authenticity and accountability regarding documents of the institution, previous enrolment and examination records. The School of Continuing Education of YCM Open University implements graduate and post graduate programmes in Hospitality, Tourism Studies, Catering Sciences , Media Graphics Animation and food sciences as follows:

- BSc Hospitality and Tourism Studies

- BSc Hospitality Studies and Catering Services

- BSc Media Graphics and Animation

- MSc Hospitality and Tourism Studies

- MSc Food Science

These programmes are implemented with the help of various 67 study centres. These study centres are spread all over Maharashtra in India. All study centres are invited physically to the head office of YCM Open University for the investigations. 15 indicators are designed for the investigations. On the basis of indicators, the documents and records are checked, of each study centre. The data collected through the interviews and cross examinations is collected and analysed. On the basis of data, the number of efficient, poor performing and nonfunctioning study centres is segregated. The problems inherent in the system are identified and suggestions proposed for the improvement in the system. This exercise proved to be beneficial for the enhancement in the services from university to the study centres and further from study centres to the students. All 67 study centres are invited for the investigation exercise but only 53 study centres attended the meeting. Among 53 study centres, 20 study centres are of B Sc Hospitality Studies and Catering Science Programme, 14 are of B Sc Hospitality and Tourism Studies, 7 are of B Sc Media Graphics and Animation programme, 5 are of M Sc Hospitality and Tourism Studies programme and 7 are of $M$ sc Food Science programme. This project had been carried out during Dec 2014 to April 2015.

First 2 parameters are about the personal information of the study centre based on name of institution, address of institution, attachment of previous recognition letters and the programme affiliated to the institute as a study centre of YCMOU. Among 67 study centres 53 ie $79 \%$ study centres attended the investigation exercise. The data collected from the study centres who attended the meeting/interview during stipulated time is analysed and following discussion and findings are reported.

\section{Discussion and findings}

The data revealed that, $100 \%$ study centres those who attended the interview, are aware about the application form, to be filled for the investigation of their study centre. They tried to provide the complete information needed in each column and every point. At some points they found some difficulties in understanding. For such points they discussed the points and then clearly reported the information. This brought to the notice of the study centres that though they are not directly under the control of University but still they will have to remain transparent and to provide the detail information.

$96 \%$ study centres those attended interview have filled the complete information asked in various columns inside the application form. Some of the study centers are found less aware about the relevant information to place at various places inside the application form hence discussed during the meeting and corrected it.

All study centres of YCM Open University are expected to maintain the correspondence details updated in University. It is revealed from the data that, $100 \%$ of study centres of all above programmes have updated their correspondence records and details in University from time to time. The study centres those who attended the meeting for investigation interviews found to be punctual to update their correspondence records which enables University to send the various instructions from time to time.

YCM Open University creates the study centre codes when the study centre is recognised after following all the necessary procedures. 
Study centres are expected to follow the same codes in future correspondence with the University. These are unique. It becomes easier to trace the records of study centre regarding enrolment and examination on digital university portal of YCMOU. In the present study, it is found that, $100 \%$ study centres followed the proper and correct study centre codes assigned to them by University.

The investigation exercise is to be carried out after every three years for the quality maintenance purpose. University has fixed the investigation fees for each programme study centre. These fees shall be paid in the form of bank demand drafts and should be attached with the application forms. It is found that, $96 \%$ study centres have paid the investigation fees at scheduled time. $4 \%$ study centres are found unable to pay the fees in time. While the interviews the study centres explained the reasons for late payment of fees. Based on the genuineness the study centresare allowed to pay the fees late.

University provides infrastructure requirement lists in a manual specially designed for the new study centres. These are provided in details for each programme separately. This manual is available on the digital university portal of YCM Open University. For investigation procedure it is expected that each and every study centre must follow the same lists to be pasted inside the application form and only quantities available with the study centres should be mentioned in the forms. From the data it is found that $72 \%$ study centres have not followed the format of infrastructure. Many of the present study centres have prepared infrastructure list on their own and not followed the instruction. All these study centres are instructed and provided the training. All these study centres have refilled the application forms after training. This exercise brought the uniformity in applications of all study centres. This later became very easy for the administrative staff for the data compilation.

University has specific norms and rules for the teachers/counsellors to be appointed at the study centres. All rules and regulations are published in the manual published for the new institutions those who wish to apply as a study centres of the university. While filling the study centre application form, there is a column where the study centreshave to fill the data objectively. Hence course wise data of teachers is asked through the investigation application. Through data, it is found that majority have not provided as expected. Hence the study centres are guided individually in an investigation meeting and the fruitful exercise is carried out. $83 \%$ of study centres have not provided course wise teachers.
Hospitality, catering science, tourism, food science programmes are mainly professional programmes. Study centre requires appropriate specialised discipline wise teachers for the implementation of programme. Most of the study centres provide this information in very casual and hazy way. After investigation meeting the study centres have updated the information properly as per the guidance. This activity increases the accountability of the study centres because they have to appoint the eligible and sufficient teachers. Ultimately this results in the quality education for the students.

University provides the details infrastructure list through the study centre manual which is published through the website. The institutions, who wish to apply for the study centre of some certain programme of the university, have to follow the rule. The institution has to provide the complete infrastructure at his place. That information should be properly submitted through the form. From the data it is found that, $87 \%$ of study centres have sufficient and appropriate infrastructure required for implementation of programme though they have not followed the appropriate proforma. During interviews, it is found that the study centres are conducting the practical sessions and theory sessions properly which requires the proper infrastructure. This made clear that though they are having the sufficient infrastructure, just due to unawareness they could not place the information in right format. Counselling through interview made them aware and they fulfilled the correct information at right places.

University provides the information about the requirement of teacher for particular programmes, through the study centre manual. The study centre manual is published on the website of University. The study centres are expected to follow the quantity norms. From the analysis, it is found that, $100 \%$ of the study centres have appropriate quantity of teachers but they are less punctual to put in a course wise format. After counselling in an interview the study centres corrected the information objectively in an application.

University provides the various formats regarding infrastructures, place specifications, teacher qualifications, biodata formats for the teachers etc. Through the study center manual. Through data it is found that, $57 \%$ of the study centres have used the proper biodata format for providing the information of teachers. $43 \%$ study centres have provided biodata in their own formats in general at the time of interview but later on they have also provide the information in correct formats. This brings the uniformity and 
ease in work of the University of maintaining the data.

It is mandatory for the study centres to provide the copies of degree certificates of each and every teacher of the study centre. This is already mentioned in the study centre manual. $53 \%$ of the study centre has provided the proofs of eligibilities and the relevant qualifications in concern with the programme. $47 \%$ of the study centres provided this information later on within provided time, after the counselling in an interview meeting.

In investigation interview meetings, it is mandatory to bring the previous enrolment records of three years. $100 \%$ study centres those attended interviews have provided previous enrolment records of the students. This data revealed that these 53 study centres were continuously functioning.

University wish to check that the study centres are properly working and taking care of education of the students. The quality of education provided to the students is dependent on the quality of education provided to the students. Hence University check the result performance of the students of the concerned study centre. From the data, it is found that $100 \%$ study centres those attended interviews have provided previous examination records of the students. This data revealed that, these 53 study centres were continuously functioning and providing services to the students.

\section{Suggestions}

The investigation exercise is organised for the whole study centers of the above mentioned programmes in methodology section above. 14 study centres have not attended the interview meeting. These study centres should be stopped for enrolling new admissions in 2015-16 academic years. This activity identified the study centres those are not punctual in attending the investigation procedure. 2 study centres that are really interested in doing this investigation exercise but due to their own difficulties could not. These study centres should be given certain time to come to the University for Investigation meeting.

\section{Conclusion}

YCMOU Study centre investigation procedure found to be very fruitful and effective procedure to make the study centres accountable and answerable to the University. Updating proper records, provision of proper infrastructures and appropriate well qualified human resource, forced study centres to remain updated with all requirements for qualitative delivery of programme to the students. Scrutiny of enrolment records and examination records proved the continuity in functioning of the study centres. The overburdened correspondence with nonfunctioning study centres for various purposes have been cut down on YCMOU system. Naturally, this offloading leads to focus and concentrate for providing efficient and timely response to study centres by YCMOU. Study centre investigation (evaluation) procedure inculcated the enhancement in discipline and quality of study centres of the mentioned programmes. It is recommended to all distance education universities to keep the regular investigation practices for the study centres that are intermediaries and important component of the system.

\section{References}

[1] Jelf, A., (2002) "Constructing quality assurance for distance education: Reflecting on what we have learnt and the potential impact on access". In H. P. Dikshit et al (Eds) Access and equity: Challenges for open and distance learning. New Delhi: Kogan Page India

[2] Yashwantrao Chavan Maharashtra Open University, History, http://ycmou.digitaluniversity.ac/Content.aspx? ID=30, (Access date: 25 October 2015)

[3] Yashwantrao Chavan Maharashtra Open University, Vision and Mission, http://ycmou.digitaluniversity.ac/ Content.aspx?ID=31, (Access date: 25 October 2015)

[4] Know-how-no-nprofit Organisation, Quality and Improvement, https://knowhownonprofit.org/Organisation/quality/man de/evaluation (Access date: 10 October 2015)

[5] Better Evaluation: Sharing information to improve evaluation, http://betterevaluation.org/theme/OrganizationalperFormance, (Access date: 7 November 2015).

[6] Reading note: Organizational evaluation, Assessment Process, http://www.fao.org/docrep/w7510e/w7510e 05.htm (Access date: 5 October 2015)

[7] Zuhairi, A., and Suparman, A., (2002) "Managing quality and accessibility in open and distance learning". In H. P. Dikshit et al (Eds) Access and equity: Challenges for open and distance learning. New Delhi:Kogan Page India 